\title{
The Impact of the Positioning of Parts on the Variable Production Costs in the Case of Additive Manufacturing
}

\author{
Peter Ficzere ${ }^{1 *}$ \\ 1 Budapest University of Technology and Economics, Faculty of Transportation Engineering and Vehicle Engineering, Department \\ of Vehicle Elements and Vehicle-Structure Analysis, H-1111 Budapest, Müegyetem rkp. 3., Hungary \\ * Corresponding author, e-mail: ficzere@kge.bme.hu
}

Received: 28 February 2020, Accepted: 10 March 2020, Published online: 15 February 2022

\begin{abstract}
Additive manufacturing is becoming increasingly widespread in many areas of life. One of the main reasons for this is that the machines, raw materials and manufacturing are becoming cheaper. The cheaper the technology, the more widespread it is. The cost of production is influenced by many factors. One of these shows the impact of the part's production positioning (placement in the working space) on costs in the following study. On this basis, we can simplify the traditional pricing strategy. From the results, we can determine how economically it is worth to place the parts in the work area of the machine.
\end{abstract}

Keywords

additive manufacturing, pricing strategies, raw material need, production time

\section{Introduction}

Due to the proliferation of additive manufacturing technologies, more and more people are engaged in either in-house production or payroll printing. In both cases, the costs have a significant role. Generally, it can be stated that the time spent on planning has decreased significantly, thus reducing the time to market (Ficzere et al., 2012; Györi and Ficzere, 2017). In many cases, there is a significant economic, competitive advantage if we can be the first to enter the market with a new product (Fedorko et al., 2019). 3D print products, also known as rapid prototypes, have a significant role in reducing the cost of errors. An important economic factor may be, where appropriate, an area called rapid tooling where prototypes or smaller series are required, e.g. the design and the manufacturing process of casting tools may be omitted. In the case of individual pieces or small series production, significant cost and time savings can be achieved as a result of abandoning tool design and manufacturing. Many direct and indirect costs can be saved by saving time (Ficzere et al., 2013; Molnár et al., 2019). Direct Material Cost ( $\mathrm{DMC}_{\mathrm{t}, \mathrm{i}}$ ) is the cost of materials that are used and can be connected to final product. In this paper DMC is time ( $\mathrm{t}$ ) and production unit (i) dependent. InDirect Material Costs ( IDMC $_{t}$ ) cannot be assigned directly to final product, activities or services that are related to more products. From modelling point of view IDMC is a time $(\mathrm{t})$ dependent variable. The term Direct Labour Cost $\left(\mathrm{DLC}_{\mathrm{t}, \mathrm{i}}\right)$ is reserved for those labour costs that can be assigned to individual units of products, for instance the labour cost of assembly line workers. In our case DLC is time $(t)$ and production unit (i) dependent. Labour costs that cannot be physically assigned to the creation of products are termed InDirect Labour Cost (IDLC $_{\mathrm{t}}$ ) and treated as part of manufacturing overhead. Indirect labour cost includes the labour costs of supervisors, materials handlers, and night security guards. Although the efforts of these workers are essential to production, it would be either impractical or impossible to accurately determine their contribution to specific units of product. In this paper IDLC is a time ( $\mathrm{t}$ ) dependent variable. Manufacturing Overhead Cost (MOC) includes items such as indirect material, indirect labour, maintenance and repairs on production equipment, heat and light, property taxes, depreciation, and insurance on manufacturing facilities. Derived from the above mentioned MOC is also time $(\mathrm{t})$ dependent variable. So Cost Of Manufacturing (COM) can be calculated by Eq. (1):

$\mathrm{COM}_{\mathrm{i}, \mathrm{t}}=\frac{\sum_{\mathrm{t}=\mathrm{t}_{0}}^{\mathrm{t}=\mathrm{t}_{1}}\left(\sum_{\mathrm{i}=1}^{n}\left(\mathrm{DMC}_{\mathrm{t}, \mathrm{i}}+\mathrm{DLC}_{\mathrm{t}, \mathrm{i}}\right)+\mathrm{IDMC}_{\mathrm{t}}+\mathrm{IDLC}_{\mathrm{t}}\right)}{n}$, 
where:

- $\mathrm{COM}_{\mathrm{t}, \mathrm{i}}:$ Cost of Manufacturing in the $\mathrm{t}$ investigation time interval (from $t_{0}$ to $t_{1}$ ) at producing unit $i$

- $\mathrm{DMC}_{\mathrm{t}, \mathrm{i}}$ : Direct Material Cost in the $\mathrm{t}$ investigation time interval (from $\mathrm{t}_{0}$ to $\mathrm{t}_{1}$ ) at producing unit $\mathrm{i}$

- $\mathrm{DLC}_{\mathrm{t}, \mathrm{i}}$ : Direct Labour Cost in the $\mathrm{t}$ investigation time interval (from $t_{0}$ to $t_{1}$ ) at producing unit $\mathrm{i}$

- $\mathrm{IDMC}_{\mathrm{t}, \mathrm{i}}:$ InDirect Material Cost in the $\mathrm{t}$ investigation time interval (from $t_{0}$ to $t_{1}$ ) at producing unit $i$

- $\operatorname{IDLC}_{\mathrm{t}, \mathrm{i}}:$ InDirect Labour Cost in the $t$ investigation time interval (from $t_{0}$ to $t_{1}$ ) at producing unit $i$

- $\mathrm{n}$ : number of produced units

Furthermore to have the Market Price (MP) the Research and Development Costs (RDC), the Revenue (R), Taxes (T) and the Marketing Costs (MC) need to be added.

$\mathrm{MP}_{\mathrm{t}, \mathrm{i}}=\mathrm{COM}_{\mathrm{t}, \mathrm{i}}+\frac{\sum_{\mathrm{t}=\mathrm{t}_{0}}^{\mathrm{t}=\mathrm{t}_{\mathrm{t}}}\left(\sum_{\mathrm{i}=1}^{n} \mathrm{RDC}_{\mathrm{t}, \mathrm{i}}+\mathrm{R}_{\mathrm{t}, \mathrm{i}}+\mathrm{T}_{\mathrm{t}, \mathrm{i}}+\mathrm{MC}_{\mathrm{t}, \mathrm{i}}\right)}{n}$,

where:

- $\mathrm{MP}_{\mathrm{t}, \mathrm{i}}$ : Market Price in the $\mathrm{t}$ investigation time interval (from $t_{0}$ to $t_{1}$ ) at producing unit $i$

- $\mathrm{RDC}_{\mathrm{t}, \mathrm{i}}$ : Research and Development Cost in the $\mathrm{t}$ investigation time interval (from $t_{0}$ to $t_{1}$ ) at producing unit $\mathrm{i}$

- $\mathrm{R}_{\mathrm{t}, \mathrm{i}}$ : Revenue in the $\mathrm{t}$ investigation time interval (from $\mathrm{t}_{0}$ to $\mathrm{t}_{1}$ ) at producing unit $\mathrm{i}$

- $\mathrm{T}_{\mathrm{t}, \mathrm{i}}$ : Taxes in the $\mathrm{t}$ investigation time interval (from $\mathrm{t}_{0}$ to $t_{1}$ ) allocated to unit $\mathrm{i}$

- $\mathrm{MC}_{\mathrm{t}, \mathrm{i}}$ : Marketing cost in the $\mathrm{t}$ investigation time interval (from $t_{0}$ to $t_{1}$ ) at producing unit $i$

With the rapid prototyping the direct costs and the indirect cost can be significantly lowered compared to regular linear production chains (Bokor, 2011). Rapid prototyping is an approach which allows crucial design decisions as early as possible (Markovits-Somogyi, 2011). Rapid prototyping is the automatic construction of physical objects using additive manufacturing technology (Ficzere et al., 2013; Ruffo et al., 2006).

It can be seen that there are a lot of components, which have effects on costs. We will investigate only the Direct Material Costs and the Direct Labour Costs.

It should be noted here that more than one completely different parts can be produced at the same time. Many factors influence the costs from the production side, in detail (Byun and Lee, 2006; Hur and Lee, 1998):
- chosen procedure,

- production time, print speed,

- placement in the work area,

- position, orientation,

- quantity requirement for support material,

- type of support material,

- percentage of fill,

- fill type,

- layer thickness,

- chosen material,

- the number of pieces to be manufactured.

On this basis, it is not surprising that there are several pricing strategies on the market (Torok et al., 2018). The present study examines the effect of only one of these position and orientation - on costs.

\section{Methodology}

During the investigation, five simple components (standard short tensile specimens) were placed in different ways and the impact of the position on costs was analyzed. Different placement methods require different support. Besides that, in each of the layouts, the machine time needed to produce the pieces also varies considerably. In the oblique position shown in Fig. 1, the use of support is required.

Beyond that, in this case, we use much material unnecessarily, properly structured printing of the support material also significantly affects machine time (Baumers et al., 2016; Zhang et al., 2015; Urbanic and Saqib, 2019). In the present study, we examine the effect of position on production time and amount of material needed.

\section{Results}

None of the layouts horizontal and vertical requires support, so there is no signifcant difference in material use,

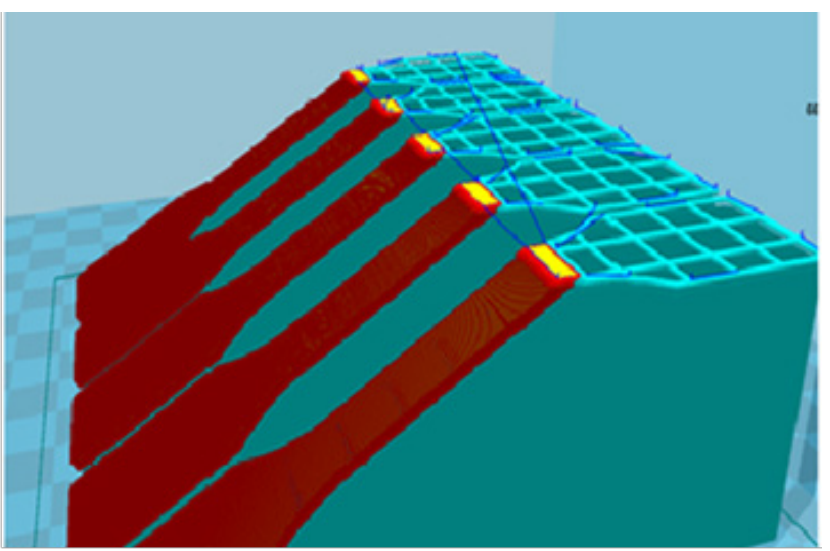

Fig. 1 Specimens printed at an angle of $30^{\circ}$; Source: own edition 
but the vertical arrangement has approx. twice the machine time. The production of specimens in oblique positions requires different amounts of support material, which also vary considerably in production time.

Fig. 2 shows the production time of the specimens as a function of the position angle. In the same way, the amount of raw material needed can be examined as a function of placement.

\section{Analysis}

One can examine Fig. 2, it is easy to see that the effect of the manufacturing position on production time and material requirements is quite similar. It is, therefore, worth examining the relationship between the amount of material used and the production time.

The resulting diagram shows that there is an approximately linear relationship between the two parameters as can be seen in Fig. 3.

Fig. 2 shows that horizontal and vertical close layouts are economical in terms of production time and material requirements.

\section{Conclusions}

Additive manufacturing companies need to be able to quote the cost of producing the models almost immediately,
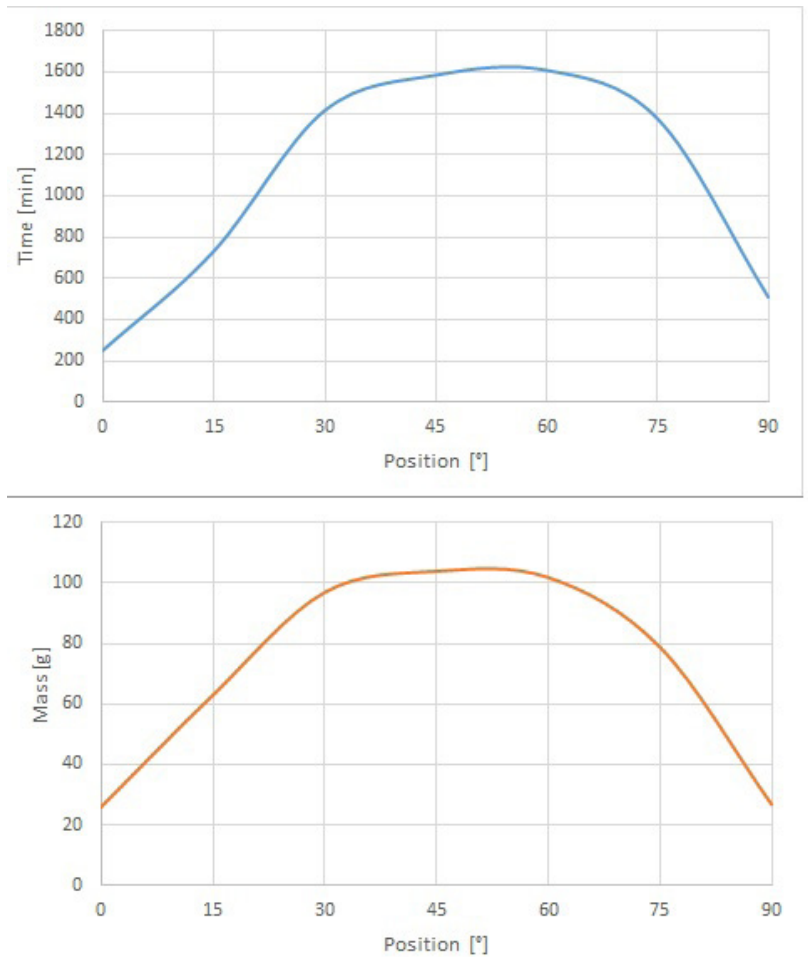

Fig. 2 Production time and raw material requirement depending on the angle of the placement; Source: own edition

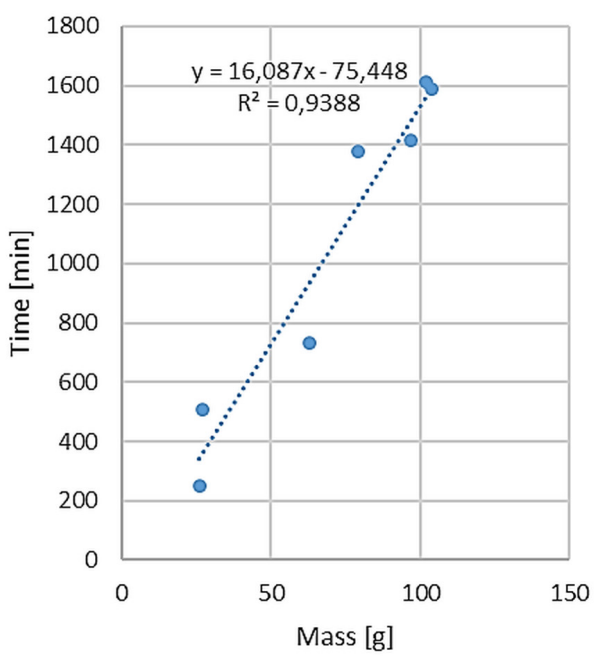

Fig. 3 Production time depends on the amount of material used

so complex relationships cannot be used to set prices. In practice, there are two types of pricing strategies (within a given technology):

\section{Calculation}

- based on the minimum height of the component,

- based on the required raw material and production time.

In the first case, the customer also can easily calculate the expected price from the geometry of the part. Here, there is an amount for a given height (production costs also change linearly with height) that the manufacturing company has calculated for all its costs, benefits.

In the second case, the price is determined by multiplying the unit price per gram of material by the total quantity of material needed and adding the machine's overhead costs.

Of course, the unit cost of materials and the hourly rate of the machine are set by the manufacturer, so that all of its costs are recovered, and there is some profit.

In both cases, determining unit prices is a serious task that requires experience in economics, corporate management and manufacturing.

Of course, there are other factors to consider when setting prices, such as uniqueness, emergency surcharge, pre- and post-processing time, and resource requirements.

Based on these, in the second case (material and timebased pricing), we get the following result.

Variable cost, VC (variable cost) can be defined as the sum of the cost of material $\mathrm{C}_{\mathrm{m}}$ (material cost), and production time-based cost $\mathrm{C}_{\mathrm{t}}$ (printing time cost). In this case the $\mathrm{C}_{\mathrm{m}}=12.5 \mathrm{Ft} / \mathrm{g}$, and the $\mathrm{C}_{\mathrm{t}}=4 \mathrm{Ft} / \mathrm{min}$ values are added. 
$\mathrm{VC}=\mathrm{C}_{\mathrm{m}}+\mathrm{C}_{\mathrm{t}}$

Based on this, we get the cost function shown in Fig. 4:

Fig. 4 shows that with such unit prices, variable costs are more sensitive to time-dependent costs.

From the graph in Fig. 4, we can determine that among the cost components, time-based cost dominates. If we change the unit price based on this, e.g. $\mathrm{C}_{\mathrm{t}}=5 \mathrm{Ft} / \mathrm{min}$ and omit the required raw material based component $\left(\mathrm{C}_{\mathrm{m}}\right)$ the following diagram can be drawn as can be seen in Fig. 5 .

It can be seen that if one simplifies costing to one component, one can still get almost the same result as the original method. The modification can simplify the pricing strategy as can be seen in Fig. 6 .

\section{Summary}

Summarizing experiences, it can be concluded that determining the market price of a product is a very complex task. Of course, the price includes many other factors besides design and production costs which are difficult to quantify. They can be the benefits of earlier market entry, as well as the results of reduced error costs. Therefore, this study examines costs exclusively from the manufacturer's perspective and focuses exclusively on direct manufacturing costs. Even with these reductions, many factors can influence costs. Thus, as a result of a further reduction, only the impact of the placement and position of the part in the workspace on costs was analyzed.

Analyses show that placement has a decisive influence on costs, as the price may even vary in magnitude as a result. It can be concluded from the results that the near horizontal and vertical states are the most cost-effective layouts.

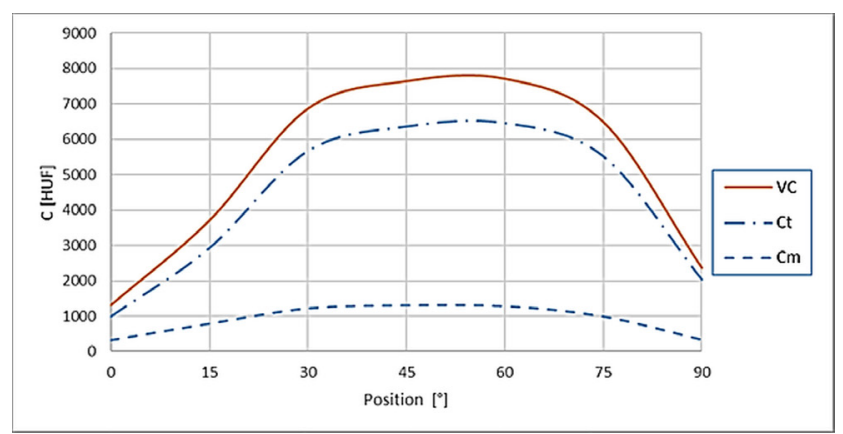

Fig. 4 Distribution of Variable Cost (VC) by Time-based Cost $\left(\mathrm{C}_{\mathrm{t}}\right)$ and Raw Material Cost $\left(\mathrm{C}_{\mathrm{m}}\right)$ depending on the part position; Source: own edition

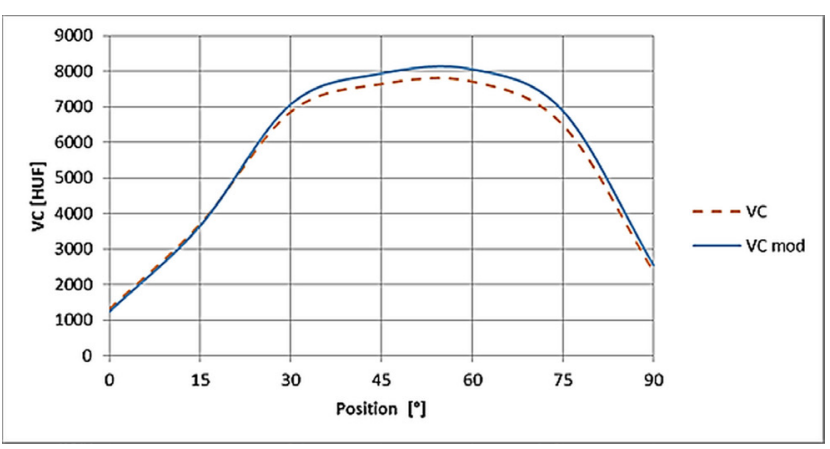

Fig. 5 Variable Cost (VC) by Manufacturing Time $\left(\mathrm{C}_{\mathrm{t}}\right)$ and Raw Material Cost $\left(\mathrm{C}_{\mathrm{m}}\right)$ and the Modified only Raw Material Based Cost (VC mod) depending on the part position; Source: own edition

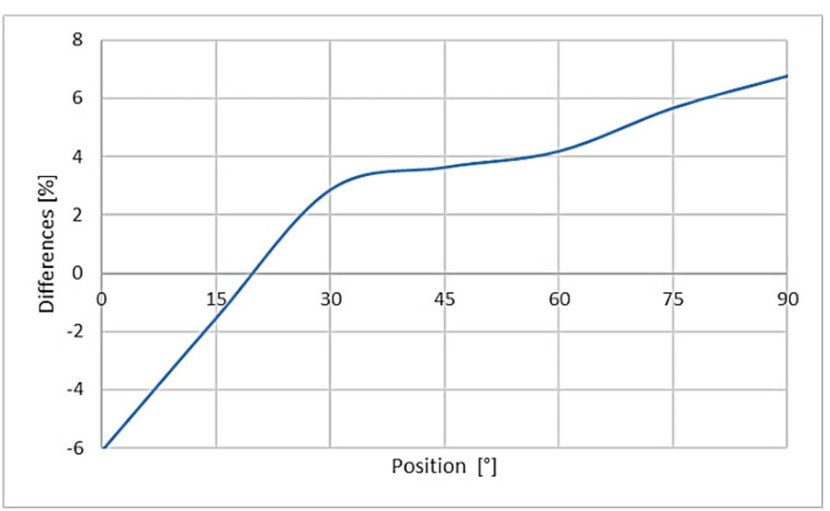

Fig. 6 Differences between the results of the two calculation methods depending on the position; Source: own edition

Of course, it is essential to emphasize that one of the significant advantages of additive technologies is the possibility of custom manufacturing. As a result, it is difficult to make general statements that are true to every piece. Since we can produce completely different geometries, even at the same time in the same workspace, processes cannot be standardized. However, it is advisable to develop a transparent pricing strategy that is understandable to the customers. The results described in this paper help us to do this, and we can even make this particular relation one-variable, based on which we can determine the price. However, since the amount of material is proportional to the time of manufacture, it is advisable to choose a time-based strategy for pricing.

One of the prerequisites for the further spread of additive manufacturing technologies is to make it as secure and transparent as possible for non-skilled people. 


\section{References}

Baumers, M., Dickens, P., Tuck, C., Hague, R. (2016) "The cost of additive manufacturing: machine productivity, economies of scale and technology-push", Technological Forecasting and Social Change, 102, pp. 193-201.

https://doi.org/10.1016/j.techfore.2015.02.015

Bokor, Z., (2011) "Calculation model for transport costing", Periodica Polytechnica Transportation Engineering, 39(1), pp. 43-47. https://doi.org/10.3311/pp.tr.2011-1.08

Byun, H. S., Lee, H. K. (2006) "Determination of the optimal build direction for different rapid prototyping processes using multi-criterion decision making", Robotics and Computer-Integrated Manufacturing, 22(1), pp. 69-80. https://doi.org/10.1016/j.rcim.2005.03.001

Fedorko, G., Molnar, V., Dovica, M., Toth, T., Soos, L., Fabianova, J., Pinosova, M. (2019) "Failure analysis of irreversible changes in the construction of car tyres", Engineering Failure Analysis, 104, pp. $399-408$.

https://doi.org/10.1016/j.engfailanal.2019.05.035

Ficzere P., Borbás L., Torok A, (2012) "Toyotarity in Rapid Prototyping", In: Borkowski, S., Năprstkovă, N. (eds.) Toyotarity: Toyota Management Principles' Interpretation in Different Branches, Oficyna Wydawnicza Stowarzyszenia Menedzerów Jakosci i Produkcji, Czestochowa, Poland, pp. 159-169.

Ficzere, P., Borbás L., Török, Á. (2013) "Economical investigation of rapid prototyping", International Journal for Traffic and Transport Engineering, 3(3), pp. 344-350. https://doi.org/10.7708/ijtte.2013.3(3).09

Győri, M., Ficzere, P. (2017) "Use of Sections in the Engineering Practice", Periodica Polytechnica Transportation Engineering, 45(1), pp. 21-24. https://doi.org/10.3311/PPtr.9144

Hur, J., Lee, K. (1998) "The development of a CAD environment to determine the preferred build-up direction for layered manufacturing", The International Journal of Advanced Manufacturing Technology, 14(4), pp. 247-254. https://doi.org/10.1007/bf01199879
Markovits-Somogyi, R. (2011) "Data envelopment analysis and its key variants utilized in the transport sector", Periodica Polytechnica, Transportation Engineering 39(2), pp. 63-68. https://doi.org/10.3311/pp.tr.2011-2.03

Molnár, V., Fedorko, G., Homolka, L., Michalik, P., Tučková, Z. (2019) "Utilisation of measurements to predict the relationship between contact forces on the pipe conveyor idler rollers and the tension force of the conveyor belt", Measurement, 136, pp. 735-744. https://doi.org/10.1016/j.measurement.2019.01.016

Ruffo, M., Tuck, C., Hague, R. (2006) "Cost estimation for rapid manufacturing - laser sintering production for low to medium volumes", Proceedings of the Institution of Mechanical Engineers, Part B: Journal of Engineering Manufacture, 220(9), pp. 1417-1427. https://doi.org/10.1243/09544054JEM517

Torok, A., Derenda, T., Zanne, M., Zoldy, M. (2018) "Automatization in road transport: a review!, Production Engineering Archives, 20(20), pp. 3-7. https://doi.org/10.30657/pea.2018.20.01

Urbanic, R. J., Saqib, S. M. (2019) "A manufacturing cost analysis framework to evaluate machining and fused filament fabrication additive manufacturing approaches", The International Journal of Advanced Manufacturing Technology, June 2019, 102(9-12), pp. 3091-3108. https://doi.org/10.1007/s00170-019-03394-x

Zhang, Y., Bernard, A., Munguia Valenzuela, J., Karunakaran, K. P. (2015) "Fast adaptive modeling method for build time estimation in Additive Manufacturing", CIRP Journal of Manufacturing Science and Technology, 10, pp. 49-60. https://doi.org/10.1016/j.cirpj.2015.05.003 